\title{
Experimental study on treating cellulose acetate wastewater based on electro-Fenton
}

\author{
Luhui Men $^{\mathrm{a}}$, Yusong Zhou ${ }^{\mathrm{b}}$, Hailin Guo ${ }^{\mathrm{c}}$ \\ The Ningbo Branch of Ordnance Science Institute of China, Ningbo 315000, China \\ aluhui317@163.com, 'bhouyusong18@sina.com, oghlfsj@126.com
}

Keywords: cellulose acetate; organic phosphorus wastewater; electro-Fenton; Fe/C particles

Abstract: The anaerobic effluent from cellulose acetate wastewater was used as experimental object, removal rates of organic phosphorus and $\mathrm{COD}_{\mathrm{Cr}}$ are used as index, the influence of reaction time, Fe/C particles, original $\mathrm{pH}$ value and current density on removal rate were investigated by electro-Fenton. The results of study show that the removal rate of organic phosphorus reaches $87.5 \%$ and the removal rate of $\mathrm{COD}_{\mathrm{Cr}}$ reaches $74.3 \%$ by adding $\mathrm{Fe} / \mathrm{C}$ particles between the electrode plates, which meets "Sewage discharge into the city sewer water quality standards Wastewater quality standards for sewage discharge to municipal sewers" (GB/T 31962-2015) Class B standard (TP<8mg/L, $\mathrm{COD}_{\mathrm{Cr}}<500 \mathrm{mg} / \mathrm{L}$ ). The optimal reaction conditions are as follows: The reaction time is 40 minutes, $\mathrm{pH}$ $=3.5$, current density is $4 \mathrm{~mA} / \mathrm{cm}^{2}$, voltage is $10.6 \mathrm{~V}$. Compared with the single electrolysis method, the introduction of $\mathrm{Fe} / \mathrm{C}$ particulates in the electrolysis system can improve the removal rates of organic phosphorus and $\mathrm{COD}_{\mathrm{Cr}}$ by $10 \% \sim 15 \%$. It provides a new idea to remove organic phosphorus in wastewater of cellulose acetate.

\section{Introduction}

Cellulose acetate production wastewater has the characteristics of complex composition, large pollutant concentration and high $\mathrm{COD}_{\mathrm{Cr}}$. The phosphorus content of its production wastewater is high due to the introduction of $\left(\mathrm{NH}_{4}\right)_{2} \mathrm{HPO}_{4}$ catalyst in the production of acetic anhydride, and partially converted to organic phosphorus. Currently, Adsorption, chemical precipitation and crystallization [1-3] are common phosphorus removal process. The above methods of removing organic phosphorus in wastewater has little effect according to preliminary experimental results, the removal rate of organic phosphorus is less than $30 \%$. The organic phosphorus content in the wastewater is still very high after biological anaerobic treatment, which is difficult to meet the "Wastewater quality standards for sewage discharge to municipal sewers" (GB/T 31962-2015) Class B standard. The advanced oxidation has become a hot research topic because of the advantages of quick reaction, no selectivity and no secondary pollution [4]. The advanced oxidation method can produce hydroxyl radical $(\bullet \mathrm{OH})$ with extremely high oxidation-reduction potential and strong oxidation property.

Common advanced oxidation processes include wet air oxidation, photo catalytic oxidation, supercritical water oxidation, electro-catalytic oxidation and ozone oxidation process [5-8], etc. The electro-catalytic oxidation method has the characteristics of cheap, easy to obtain experimental materials and wide application range. Its basic principle is to produce $\mathrm{H}_{2} \mathrm{O}_{2}$ on the surface of a suitable cathode materials by the oxidation-reduction reaction (ORR) of two electrons [9-10], as shown in formula (1), (2). The anaerobic effluent from cellulose acetate production wastewater was used as experimental object. The influence of reaction time, $\mathrm{Fe} / \mathrm{C}$ particles, original $\mathrm{pH}$ value and current density on removal rate were investigated by electrolysis method of advanced oxidation processes. The treatment method of introducing $\mathrm{Fe} / \mathrm{C}$ particulates filler into the electrolysis reaction system was proposed, which improve the removal efficiency of organic phosphorus and $\mathrm{COD}_{\mathrm{Cr}}$ effectively. It provides a new idea to remove organic phosphorus in wastewater from cellulose acetate production.

$$
\begin{aligned}
\mathrm{O}_{2}+2 \mathrm{H}^{+}+2 \mathrm{e}^{-} & \rightarrow \mathrm{H}_{2} \mathrm{O}_{2} \\
\mathrm{Fe}^{2+}+\mathrm{H}_{2} \mathrm{O}_{2} & \rightarrow\left[\mathrm{Fe}(\mathrm{OH})_{2}\right]^{2+} \rightarrow \mathrm{Fe}^{3+}+\mathrm{OH}^{-}+\cdot \mathrm{OH}
\end{aligned}
$$




\section{Experimental}

Experimental devices, materials and apparatus

Experimental devices : (1)UASB anaerobic reactor was purchased from Shanghai Tongguang Science and Education Instrument Co., Model: TG -271 , inlet flow rate: $2 \sim 5 \mathrm{~L} / \mathrm{h}$, cylinder diameter: $\Phi 150 \mathrm{~mm} \times 2000 \mathrm{~mm}$, (2) Electro - Fenton reaction device is self - made square reactor. The size of reactor: $150 \mathrm{~mm} \times 200 \mathrm{~mm} \times 150 \mathrm{~mm}$. The steel electrode plates coated Titanium were placed on both sides of the reactor, the aeration device is placed at the bottom of the reactor between the two plates, The electrode plates are connected with a regulated DC power. The effective electrolytic area is 140 $\mathrm{cm}^{2}$.

Experimental materials : (1)Wastewater was from a chemical industry company in Ningbo, the $\mathrm{COD}_{\mathrm{Cr}}$ of anaerobic effluent is about $1000 \mathrm{mg} / \mathrm{L}$, The concentration of organic phosphorus is about 60 $\mathrm{mg} / \mathrm{L}, \mathrm{pH} \approx 7.5$; (2) Iron filings, activated carbon, sodium silicate and calcium carbonate are burned into $\mathrm{Fe} / \mathrm{C}$ particles by $6: 2: 1.5: 0.5$; (3) All other reagents used in the experiment were analytical reagents.

Experimental apparatus: (1) UV-visible spectrophotometer was purchased from Shanghai Analytical Instrument Co., Model: UV-5500(PC); (2) PHS-3C pH meter; (3) Chemical oxygen demand analyzer, Model: COD-572.

Experimental process and method

Experimental process: the $\mathrm{pH}$ of original wastewater adjusted to 7.5-8 moved to the sewage tank with capacity of $40 \mathrm{~L}$, start peristaltic pump, wastewater was transferred to the UASB anaerobic reactor for 24 hour in the condition of $30^{\circ} \mathrm{C}$, and the anaerobic effluent of cellulose acetate production wastewater is transferred to a $\mathrm{pH}$ adjustment tank, the $\mathrm{pH}$ of anaerobic effluent was adjusted to $3 \sim 4$, and then wastewater was transferred to electro - Fenton reactor; Wastewater electrolyzed was subside with $\mathrm{CaCO}_{3}$ at last. The experimental apparatus is shown as Fig.1.

Experimental method: The influence of reaction time, original $\mathrm{pH}$ value and current density on the removal rates of organic phosphorus and $\mathrm{COD}_{\mathrm{Cr}}$ were studied by controlling variables, and compare the results whether Fe/C particles are added or not.

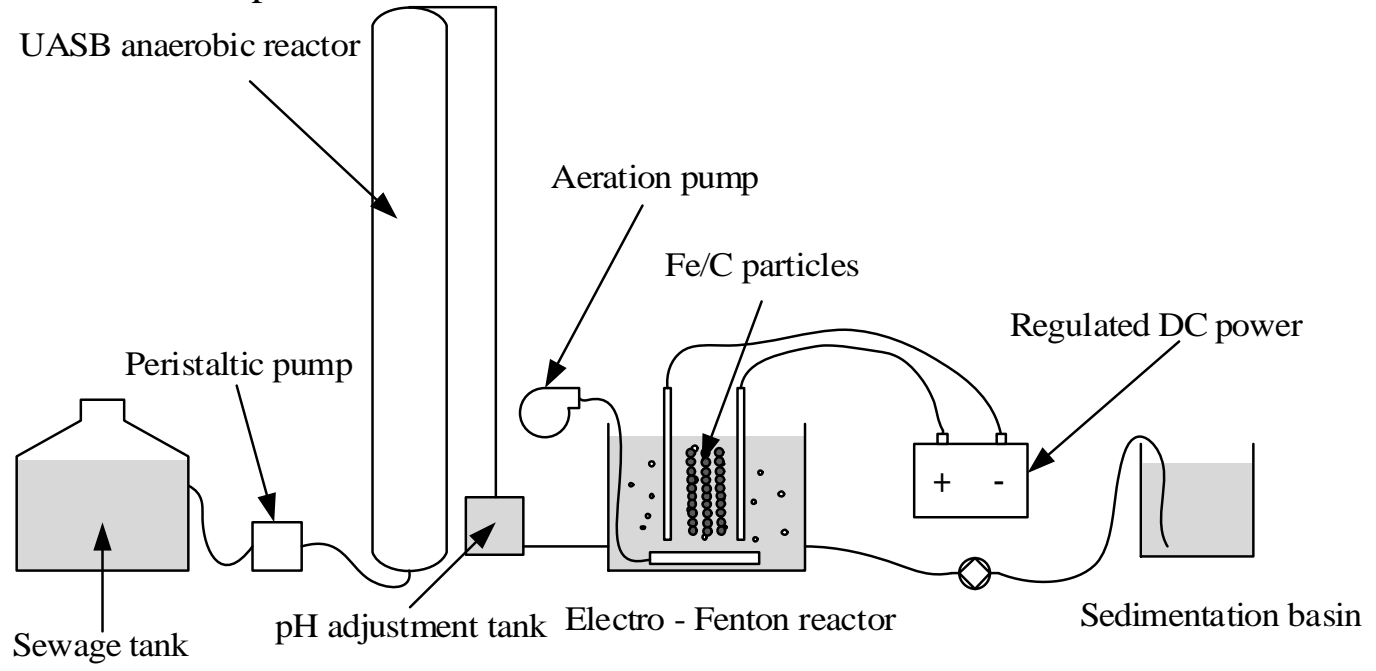

Fig.1 Experimental devices

\section{Analytical method and Data processing}

The organic phosphorus was measured using chloroform extraction combined with "Water quality-Determination of total phosphorus-Ammonium molybdate spectrophotometric method" (GB11893-89). Take $250 \mathrm{~mL}$ wastewater sample placed in $500 \mathrm{~mL}$ separating funnel and add $8 \mathrm{~g}$ of 
sodium chloride, the organic phosphorus was extracted for three times with $30 \mathrm{ml}$ of chloroform. $25 \mathrm{~mL}$ of water, $5 \mathrm{~mL}$ of $10 \% \mathrm{~K}_{2} \mathrm{~S}_{2} \mathrm{O}_{4}$ and $1 \mathrm{~mL}$ of $5 \mathrm{~mol} / \mathrm{L} \mathrm{H}_{2} \mathrm{SO}_{4}$ were added to the extraction. The extraction was heated to evaporate chloroform at low temperature and micro-boiled 30min, and wait for cooling to indoor temperature. Then total phosphorus of the sample is detected by GB-11893-89. So TP hereinafter measured is organic phosphorus content of the sample. The COD in wastewater is determined by "Water quality-Determination of chemical oxygen demand-Dichromate method" (GB11914-1989). The removal rates were calculated according to equation (3), (4):

$$
\begin{gathered}
\eta_{C O D}=\frac{C O D_{0}-C O D_{i}}{C O D_{0}} \times 100 \% \\
\eta_{T P}=\frac{T P_{0}-T P_{i}}{T P_{0}} \times 100 \%
\end{gathered}
$$

$\eta$ represents the removal rate. $(\%)$

$\mathrm{COD}_{0}$ represents $\mathrm{COD}_{\mathrm{Cr}}$ before treatment. $(\mathrm{mg} / \mathrm{L})$

$\mathrm{COD}_{\mathrm{i}}$ represents $\mathrm{COD}_{\mathrm{Cr}}$ after treatment. $(\mathrm{mg} / \mathrm{L})$

$\mathrm{TP}_{0}$ represents the organic phosphorus content before treatment. $(\mathrm{mg} / \mathrm{L})$

$\mathrm{TP}_{\mathrm{i}}$ represents the organic phosphorus content after treatment. $(\mathrm{mg} / \mathrm{L})$

\section{Experimental results and discussion}

Influence of time

The influence of time on the removal rates of organic phosphorus and $\mathrm{COD}_{\mathrm{Cr}}$ was studied in the condition of the temperature of $25^{\circ} \mathrm{C}$, original $\mathrm{pH}=3.5$, current density $=4 \mathrm{~mA} / \mathrm{cm}^{2}$ and voltage $=$ 10.6V. The experimental results were shown in Fig.2
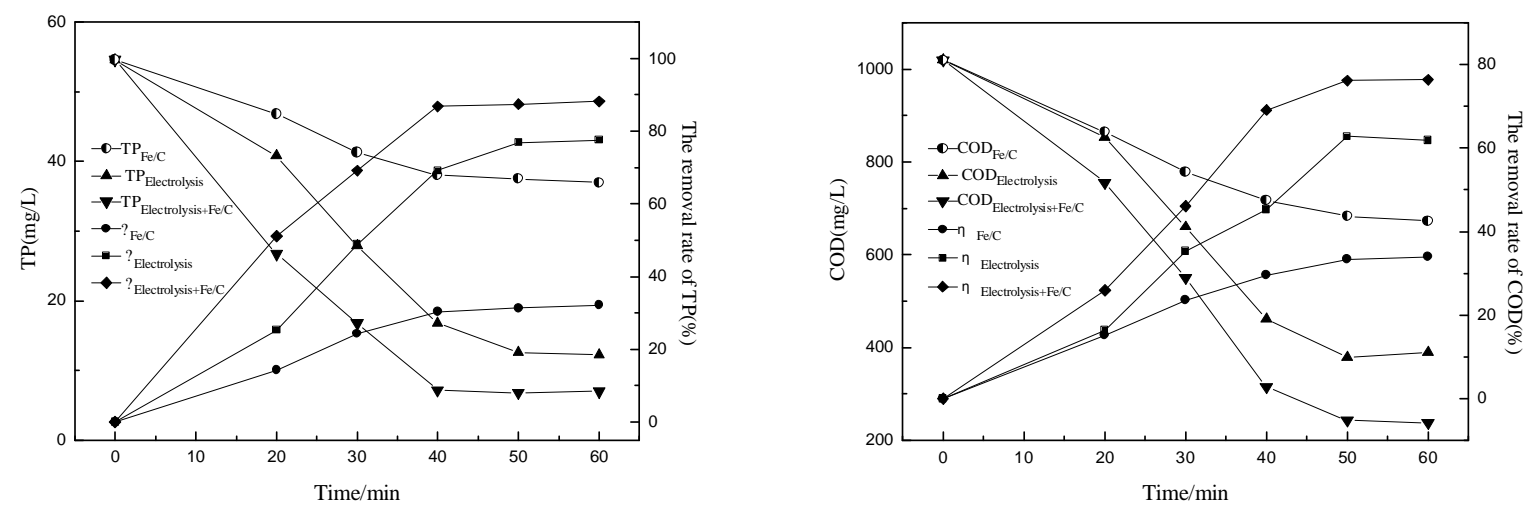

Fig.2 Influence of time on removal rates of organic phosphorus and $\mathrm{COD}_{\mathrm{Cr}}$

The experimental results show that the concentration of organic matter continues to decrease and the removal rates of organic phosphorus and $\mathrm{COD}_{\mathrm{Cr}}$ increase more and more slowly with extension of time. The removal rate can reach its peak faster by using electrolysis $+\mathrm{Fe} / \mathrm{C}$. In the conditions of single $\mathrm{Fe} / \mathrm{C}$ micro-electrolysis, the removal rate of organic phosphorus stabilized at $32 \%$ after 50 minutes $(\mathrm{TP} \approx 37 \mathrm{mg} / \mathrm{L})$, and the removal rate of $\mathrm{COD}_{\mathrm{Cr}}$ stabilized at $31 \%\left(\mathrm{COD}_{\mathrm{Cr}} \approx 680 \mathrm{mg} / \mathrm{L}\right)$. In the conditions of single electrolysis, the removal rate of organic phosphorus stabilized at $76 \%$ after $40 \mathrm{~min}$ $(\mathrm{TP} \approx 12 \mathrm{mg} / \mathrm{L})$, and the removal rate of $\mathrm{COD}_{\mathrm{Cr}}$ stabilized at $60 \%\left(\mathrm{COD}_{\mathrm{Cr}} \approx 385 \mathrm{mg} / \mathrm{L}\right)$. In the conditions of electrolysis+ $\mathrm{Fe} / \mathrm{C}$ particles : If the above two methods are irrelevant and the reduction of organic matter concentration resulting in reduced removal rate wasn't took into account, the removal rate of $\mathrm{COD}_{\mathrm{Cr}}$ should be calculated as follow: $\eta_{\mathrm{COD}} \leq 1-(1-60 \%) \times(1-31 \%)=72 \%$; the removal rate of $\mathrm{TP}$ should be calculated as follow: $\eta_{\mathrm{TP}} \leq 1-(1-76 \%) \times(1-32 \%)=83 \%$. But experiment result shows that the 
removal of $\mathrm{COD}_{\mathrm{Cr}}$ reach a peak of $76 \%(>73 \%)$ at $50 \mathrm{~min}\left(\mathrm{COD}_{\mathrm{Cr}} \approx 240 \mathrm{mg} / \mathrm{L}\right)$ and the removal of $\mathrm{TP}$ reach a peak of $87.6 \%(>83 \%)$ at 40 minutes $(\mathrm{TP} \approx 7 \mathrm{mg} / \mathrm{L})$. The experimental results show that $\mathrm{Fe} / \mathrm{C}$ combined with electrolysis have weak synergistic effect.

The main reasons for the experimental results are as follow after analysis: (1) the concentration of organic matter continues to decrease with the process of reaction, the probability of collision of hydroxyl radicals and organic matter reduce significantly. The probability of effective collision approaches 0 when the concentration of organic matter is extremely low; (2) when Fe/C particles were added into the electrolysis reaction system, on the one hand, $\mathrm{Fe} / \mathrm{C}$ micro-electrolysis can not only promote the degradation of organic matter but also many new tiny electrodes formed under the action of electrodes;(3) Fe/C particles can provide $\mathrm{Fe}^{2+}$ for Fenton reaction under acidic conditions and improve the efficiency of the electrolysis method.

\section{Influence of original $\mathrm{pH}$}

The influence of original $\mathrm{pH}$ on the removal rates of organic phosphorus and $\mathrm{COD}_{\mathrm{Cr}}$ was studied in the condition of the temperature of $25^{\circ} \mathrm{C}$, time $=40$ minutes, current density $=4 \mathrm{~mA} / \mathrm{cm}^{2}$ and voltage $=10.6 \mathrm{~V}$. The experimental results were shown in Fig.3.
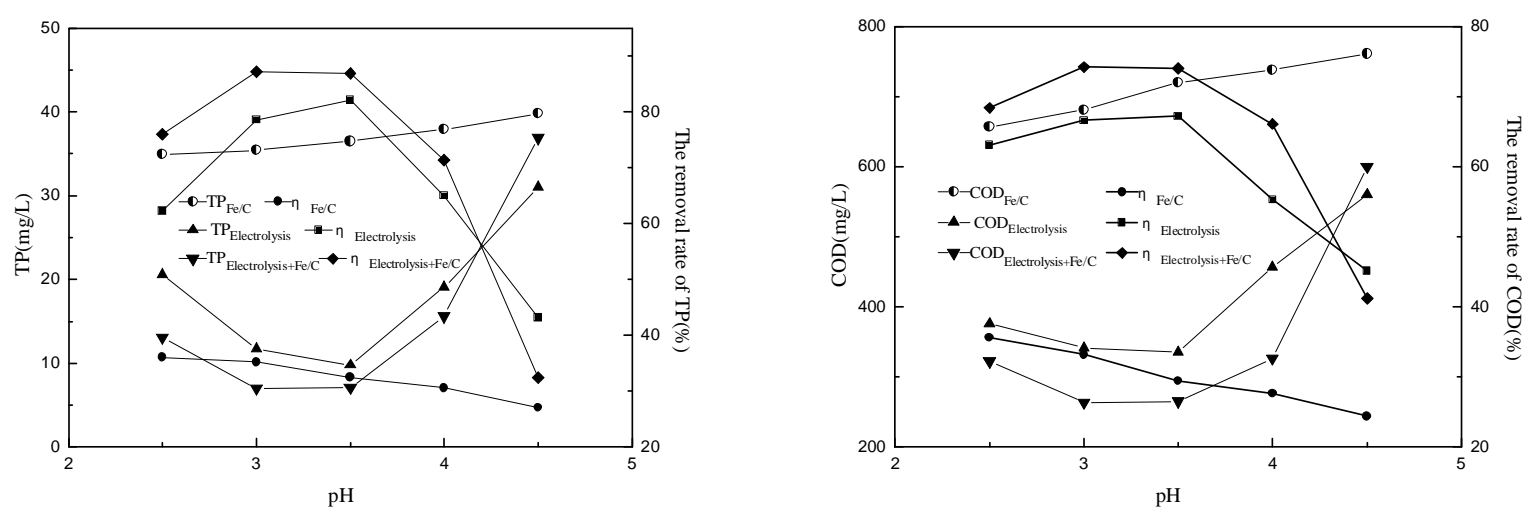

Fig.3 Influence of original $\mathrm{pH}$ on removal rates of organic phosphorus and $\mathrm{COD}_{\mathrm{Cr}}$

The experimental results was shown as Fig.3: In the conditions of single Fe/C micro-electrolysis, the removal rates of organic phosphorus and $\mathrm{COD}_{\mathrm{Cr}}$ decrease faster and faster with the increase of $\mathrm{pH}$ value. The removal rate of organic reach $33 \%(\mathrm{TP}=35 \mathrm{mg} / \mathrm{L})$ when original $\mathrm{pH}$ is 2.5 , and the removal rate of $\mathrm{COD}_{\mathrm{Cr}}$ reach $32 \%\left(\mathrm{COD}_{\mathrm{Cr}}=655 \mathrm{mg} / \mathrm{L}\right)$. In the conditions of single electrolysis, the removal rates of organic phosphorus and $\mathrm{COD}_{\mathrm{Cr}}$ slowly increase at $\mathrm{pH}=2.5 \sim 3.5$, the effect of treatment decrease significantly when original $\mathrm{pH}$ continue to be increased. The removal rate of organic phosphorus stabilized at $80 \%(\mathrm{TP} \approx 11 \mathrm{mg} / \mathrm{L})$ when $\mathrm{pH}=3 \sim 3.5$, and the removal rate of $\mathrm{COD}_{\mathrm{Cr}}$ stabilized at $67 \%$ $\left(\mathrm{COD}_{\mathrm{Cr}} \approx 335 \mathrm{mg} / \mathrm{L}\right)$. In the conditions of electrolysis+ $\mathrm{Fe} / \mathrm{C}$ particles, the removal rates of organic phosphorus and $\mathrm{COD}_{\mathrm{Cr}}$ slowly increase at $\mathrm{pH}=2.5 \sim 3.5$, the effect of treatment decrease quickly when original $\mathrm{pH}$ continues to be increased. The removal rates of organic phosphorus stabilized at $87 \%$ $(\mathrm{TP} \approx 7 \mathrm{mg} / \mathrm{L})$ when $\mathrm{pH}=3 \sim 3.5$, and the removal rate of $\mathrm{COD}_{\mathrm{Cr}}$ stabilized at $74.3 \%\left(\mathrm{COD}_{\mathrm{Cr}} \approx 260 \mathrm{mg} / \mathrm{L}\right)$. The $\mathrm{pH}=3.5$ is the optimal value because acid is needed to adjust $\mathrm{pH}$ before electrolysis.

The main reasons are as follows according to the reaction (1), (2) after analysis: the concentration of $\mathrm{H}^{+}$is sufficient to maintain the progress of the reaction at $\mathrm{pH}=2.5 \sim 3.5$. The secondary reaction $2 \mathrm{H}^{+}$ $+2 \mathrm{e}^{-}=\mathrm{H}_{2}$ was exacerbated and hinder the formation of $\mathrm{H}_{2} \mathrm{O}_{2}$ when the $\mathrm{pH}$ is low. The concentration of $\mathrm{H}^{+}$becomes the main factor that restricts the reaction and the generation of hydroxyl radical is limited at $\mathrm{pH}>3.5$. Fe were oxidized by $\mathrm{H}^{+}$under acidic conditions, which exacerbate consumption of $\mathrm{H}^{+}$and retard the degradation of pollutants. 
Influence of current density

The influence of current density on the removal rates of organic phosphorus and $\mathrm{COD}_{\mathrm{Cr}}$ was studied in the condition of the temperature of $25^{\circ} \mathrm{C}$, time $=40$ minutes, $\mathrm{pH}=3.5$ and voltage $=10.6 \mathrm{~V}$. The experimental results were shown in Fig.4.
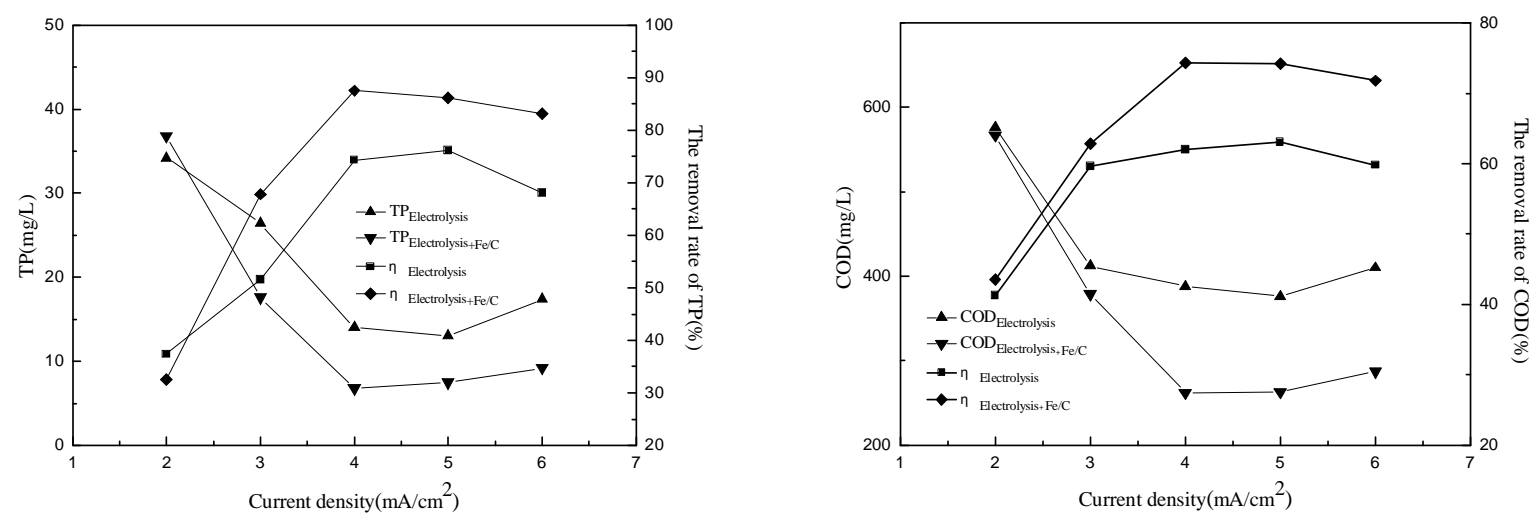

Fig.4 Influence of current density on removal rates of organic phosphorus and $\mathrm{COD}_{\mathrm{Cr}}$

The experimental results show that the removal rates of organic phosphorus and $\mathrm{COD}_{\mathrm{Cr}}$ increase rapidly with the increase of current density when current density is between $2 \mathrm{~mA} / \mathrm{cm}^{2}$ and $4 \mathrm{~mA} / \mathrm{cm}^{2}$. In the conditions of single electrolysis, the removal rate of organic phosphorus and $\mathrm{COD}_{\mathrm{Cr}}$ reach $76.2 \%$ $(\mathrm{TP}=13 \mathrm{mg} / \mathrm{L})$ and $63.1 \%(376 \mathrm{mg} / \mathrm{L})$ respectively when the current density was $5 \mathrm{~mA} / \mathrm{cm}^{2}$; In the conditions of electrolysis $+\mathrm{Fe} / \mathrm{C}$ particles, the removal rate of organic phosphorus and $\mathrm{COD}_{\mathrm{Cr}}$ reach $87.5 \%(\mathrm{TP}=6.8 \mathrm{mg} / \mathrm{L})$ and $74.3 \%\left(\mathrm{COD}_{\mathrm{Cr}}=262 \mathrm{mg} / \mathrm{L}\right)$ respectively when the current density was $4 \mathrm{~mA} / \mathrm{cm}^{2}$. The removal rates of organic phosphorus and $\mathrm{COD}_{\mathrm{Cr}}$ decrease slightly when the current density continues to be increased. The addition of Fe/C particles increase the peak of current density and the removal rates of organic phosphorus and $\mathrm{COD}_{\mathrm{Cr}}$.

The main reasons are as follows: The secondary reaction $\mathrm{H}_{2} \mathrm{O}_{2}+2 \mathrm{H}^{+}+2 \mathrm{e}^{-} \rightarrow 2 \mathrm{H}_{2} \mathrm{O}$ was exacerbated rapidly with the increase of voltage when voltage is too high, the consumption of effective substances increases, and the removal rate of organic phosphorus and $\mathrm{COD}_{\mathrm{Cr}}$ decrease. On the other hand, addition of $\mathrm{Fe} / \mathrm{C}$ particulates filler increases the cathode area and improves utilization of electron and achieve higher peak of current density.

\section{Conclusions}

(1) The anaerobic effluent of cellulose acetate wastewater was treated by electrolysis $+\mathrm{Fe} / \mathrm{C}$, the removal rate of organic phosphorus reached $87.5 \%, \mathrm{TP}=6.8 \mathrm{mg} / \mathrm{L}<8 \mathrm{mg} / \mathrm{L}, \mathrm{COD}_{\mathrm{Cr}}$ removal rate reached $74.3 \%, \mathrm{COD}_{\mathrm{Cr}}=262 \mathrm{mg} / \mathrm{L}<300 \mathrm{mg} / \mathrm{L}$, which meet the "Wastewater quality standards for sewage discharge to municipal sewers" (GB/T 31962-2015) Class B standard. The optimal reaction conditions are as follows: The reaction time is 40 minutes, $\mathrm{pH}=3.5$, current density is $4 \mathrm{~mA} / \mathrm{cm}^{2}$, voltage is $10.5 \mathrm{~V}$.

(2) Compared with the single electrolysis method, the introduction of $\mathrm{Fe} / \mathrm{C}$ particulates in the electrolysis system can improve the removal rates of organic phosphorus and $\mathrm{COD}_{\mathrm{Cr}}$ by $10 \% \sim 15 \%$.

\section{References}

[1] Tang Chaochun, Chen Huimin, Liu Ming and Ye Xin: Research progress in the use of adsorption for dephosphorization, Industrial Water Treatment 37(5) (2015): 1-4. 
[2] Meng Shunlong, Qiu Liping, Chen Jiazhang and Xu Pao: The Research Process of Chemistry Precipitation Method in Phosphorus Removal in Wastewater, Chinese Agricultural Science Bulletin, 28(35) (2012):264-268.

[3] Zhou Donglai, Bai Xiangyu: Study on recovering nitrogen and phosphorus from sludge using Struvite crystallization method, Modern Chemical Industry 35(8) (2015):137-140.

[4] Li Shanshan, Liu Junfeng and Feng Yujie: Research development of pesticide wastewater treatment by advanced oxidation technique, Industrial Water Treatment 37(5) (2015): 6-10

[5] Li Ying: Removing chroma from printing ink wastewater by ozone oxidation process, Industrial Water \& Wastewater 46(6) (2012): 44-46.

[6] Tang Xingying, Wang Shuzong and Qian Lili: Treatment of organic phosphorus pesticides manufacturing wastewater by supercritical water oxidation, Advanced Materials Research 788(2013):434-439

[7] Meng Wei: Research of Electric Catalytic Oxidation to Treat Butyl Xanthate and Aminodithphosphate Wastewater, D. Central South University 2012.

[8] Ning Jun, Chen Liwei and Cai Tianming: Degradation mechanism of aniline by ozonation catalysis, Chinese Journal of Environmental Engineering 7(2) (2013): 551-556.

[9] Zhou Lei, Zhou Minghua: Review on the Electro-Fenton Technology, Technology of Water Treatment 39(10) (2013): 6-10.

[10] Huang Lizhu, Zhang Shen, Chen Huadong: Paper-making wastewater treatment by Fenton oxidation process, Industrial Water \& Wastewater 47(6) (2016): 36-38. 